\title{
Evaluation of the effectiveness of educational technology in the prevention of falls in the surgical medical clinic
}

\author{
Amanda de Oliveira Barbosa ${ }^{1}$, Thamires Sales Macêdo*1, Francisco Marcelo Leandro Cavalcante ${ }^{1}$, Ingrid Kelly Morais \\ Oliveira ${ }^{1}$, Joselany Áfio Caetano ${ }^{2}$, Lívia Moreira Barros ${ }^{3}$ \\ ${ }^{1}$ School of Nursing, Vale do Acaraú State University, Sobral, Brazil \\ ${ }^{2}$ School of Nursing, Federal University of Ceara, Fortaleza, Brazil \\ ${ }^{3}$ University of International Integration of Afro-Brazilian Lusophony, Brazil
}

Received: August 25, 2020

DOI: $10.5430 /$ jnep.v11n4p1
Accepted: November 22, 2020

Online Published: December 13, 2020

\begin{abstract}
Objective: To evaluate the effectiveness of a flipchart as an educational technology for patient education on preventing falls in hospitalized patients.

Methods: This is a quasi-experimental study, being a pilot study type, with a quantitative approach, carried out in a hospital in the northern region of the State of Ceará, Brazil. Thirty-one patients represented the sample from August to November 2019. For the collection of information, it has been applied a structured instrument that includes two parts: a) Clinical-epidemiological data; b) Fall prevention knowledge test.

Results: In the pre-test, there was a median of correct answers of 17 (interquartile range $=8$ ), while in the post-test the median of correct answers was 20 (interquartile range $=6$ ). Significance was observed in the increase in average of theoretical correct answers $(p<.000)$.

Conclusions: The flipchart is an effective technology to be used in health education to prevent falls, favoring an increased perception of risks in the hospital environment.
\end{abstract}

Key Words: Accidental falls, Patient safety, Educational technology, Health education, Nursing

\section{INTRODUCTION}

Fall is defined as an event that causes a person to inadvertently lay on the ground, on the floor or at another lower level, and stand out among injuries from external causes, representing the second leading cause of unintended deaths worldwide. ${ }^{[1]}$ It is estimated that individuals who suffer falls have, on average, 12.3 more days of hospitalization and the occurrence of such an adverse event can increase hospital costs by up to $61 \% .^{[2]}$

In-hospital falls are preventable accidents, but they continue to be a problem of high prevalence on patient safety, being related to longer hospital stay and clinical risk factors, such as visual impairment, balance difficulties, assistance in manual transferring and urinary incontinence, in addition to the use of multiple medications. ${ }^{[3]}$

Therefore, its prevention becomes an important issue in the

\footnotetext{
*Correspondence: Thamires Sales Macêdo; Email: thamiressales1998@ outlook.com; Address: School of Nursing, Vale do Acaráu State University, Sobral, Brazil.
} 
hospital environment and other health institutions in different countries. In Brazil, the National Patient Safety Program (PNPS) was created, with six goals, among them, the prevention of falls, aiming at improving service to society, through training, awareness campaigns and encouraging good practices in care with an emphasis on organizational improvement, in addition to providing patient safety guides, manuals and protocols. ${ }^{[4,5]}$

In this perspective, the use of educational strategies for the prevention of falls has obtained positive results. Recent update of the Cochrane review that analyzes interventions about hospital and residential care concluded that multifactorial intervention (addressing risk factors for multiple falls, usually based on the risk of falls assessment in individual patients) was the only intervention that can be effective in reducing falls rate. ${ }^{[6]}$

For this process to be successful, health professionals must appropriate dynamic and current means that can instigate patient learning. For that, educational technologies stand out as an excellent pedagogical tool, as they allow patients to know about their clinical conditions and to learn ways to perform their self-care, optimizing one's perceptions on their limitations, which can change positively in health behavior. $^{[7,8]}$

In a previous study, the flipchart "Be careful not to fall" was constructed and validated, which is an educational technology with an attractive layout and content about prevention of falls in the hospital environment that facilitates passing on information during health education and makes the process of teaching-learning more dynamic. However, to disseminate its use to health professionals who work in hospital institutions, it is necessary to verify whether this technology is effective in improving the knowledge of individuals who participate in the educational intervention mediated by the flipchart.

Thus, this study aims to evaluate the effectiveness of a flipchart as an educational technology for the prevention of falls in hospitalized patients.

\section{METHOD}

This is a quasi-experimental study, being a pilot study type, with a quantitative approach, carried out at a hospital in the northern region of the State of Ceará, a regional and state reference in highly complex health care. The study included 31 patients admitted to the medical clinic from September to November 2019.

Inclusion criteria for the sample of patients were: being over 18 years old, being hospitalized for a minimum period of 24 hours and being literate. Exclusion criteria were: patients with visual or hearing impairment or cognitive impairment and hemodynamic instability. Exclusion of patients with visual, hearing or cognitive impairments is justified by the impossibility of seeing those images in the flipchart as well as reading and/or interpreting its information. Hemodynamically unstable patients were excluded due to the risk of complications at the time of educational intervention.

For the collection of data, a structured instrument was applied, which includes two parts: 1. Clinical-epidemiological data and 2. Knowledge test on prevention of falls, which was applied before and after the application of the flipchart.

During evaluation of clinical and epidemiological data, information was collected such as sex, age, skin color (selfreported), marital status, educational level, origin, incomes, medical diagnosis and medications in use. Patients' knowledge about falls prevention was measured through the test that contained 20 statements about the content covered in the fall prevention flipchart, to which the participant should answer "true" or "false". This instrument was built by the researchers of this study and was validated by three nurse doctors with expertise in educational technologies and patient safety.

Participants were approached individually in wards and informed about the ethical aspects and about the objective of the study. The educational intervention mediated by the flipchart took place next to each patient's bed, in the morning and/or afternoon shifts, with an average duration of 30 minutes. It is worth mentioning that the flipchart was shown only once and, after the end of the educational intervention, the researcher was available to clarify doubts.

This flipchart consists of 18 pages that contain a cover, a technical page, the presentation and seven colorful and dynamic illustrations, which demonstrate in a self-explanatory way the risks of falls that are prevalent in the hospital environment where patients are inserted. The educational instrument was divided into seven topics: the definition of falls; the role of a nursing team in preventing falls; risk factors for falls in a hospital environment; risk factors for falls associated with the patient's clinical condition; fall prevention surveillance; muscle strengthening exercises and guidance if a patient falls.

In order to give greater significance to this educational technology, the material was validated by 7 expert nurses in patient safety, educational technologies or assistance in the hospital environment, to assess the text, language, image design, colors and content adaptation. After the descriptive analysis of the data referring to the characterization of the 
judges, the Content Validity Index (CVI) equal to 1, 0 was obtained.

For data analysis, Excel program was used to tabulate and organize data in spreadsheets. Subsequently, statistical analysis was performed with the Statistical Package for the Social Sciences (SPSS) program to obtain absolute and percentage frequencies, average and standard deviation. Each question on the knowledge assessment questionnaire was submitted to the McNemar test to compare the change in status between pre and post-tests. Wilcoxon test was also used to compare medians and interquartile ranges of total correct responses between pre and post-test. The level of significance adopted in all tests was 5\% and confidence interval was 95\%.

This study followed Resolution 466/12 of the National Health Council, regarding the principles of Bioethics autonomy, beneficence, non-maleficence and justice. ${ }^{[9]}$ Participants were informed about the risks and benefits of the research, accepting to participate in the study through signing the Informed Consent Form (ICF). Ethics and Research Committee of the Universidade Estadual Vale do Acaraú has approved the project under opinion number 3,685,707.

\section{RESULTS}

Table 1 shows the clinical and epidemiological profile found.

Regarding knowledge, there was an average of 17 correct answers (interquartile range $=8$ ) in the pre-test, while in the post-test the average number of correct answers was 20 (interquartile range $=6$ ). Thus, there was a significant increase in the average of theoretical correct answers $(p<.000)$. Table 2 shows the success rates for each question of the knowledge test.

As noted in Table 2, questions that brought the highest number of correct answers after the educational intervention with the flipchart addressed the definition of falls ( $p$-value: .000), falls in obese patients ( $p$-value: .030), behavior in case of a fall in the hospital environment and need to call the nursing staff ( $p$-value: .006), conducts if falling at home ( $p$-value: $.000)$ and in case of injury after the adverse event ( $p$-value: $.004)$.

\section{Discussion}

In this study, there was a prevalence of male patients, aging 37.06 years old, single, with elementary education, presenting trauma conditions and history of falls. The predominant profile of trauma patients can be explained by the demand for assistance from the studied hospital, since the institution is a reference for trauma in the state of Ceará, a region known for the lack of safety accessories used by population, such as helmets, and the high rate of automobile accidents.

Regarding sex and age, a study conducted in Rio Grande do Sul converges with the predominance of male patients hospitalized, but differs in relation to age, in which the age group above 60 years prevailed with a greater association with the risk of falls. ${ }^{[10]}$ Another study also conducted in Rio Grande do Sul highlights the predominant profile of women also with a higher prevalence of age above 60 years. Authors also state that low education interferes with adherence to preventive care for falls by hospitalized patients. ${ }^{[1]}$

Table 1. Epidemiological and clinical characterization of patients hospitalized in medical clinic $(n=31)($ Sobral/CE, Brazil, 2019)

\begin{tabular}{|c|c|c|}
\hline Variable & $\mathbf{N}$ & $\%$ \\
\hline \multicolumn{3}{|l|}{ Sex } \\
\hline Male & 18 & 58.1 \\
\hline Female & 13 & 41.9 \\
\hline Average age (standart deviation) & \multicolumn{2}{|c|}{$37.06( \pm 15.40)$} \\
\hline \multicolumn{3}{|l|}{ Scholarship } \\
\hline Elementary School & 14 & 42.5 \\
\hline College degree & 11 & 35.5 \\
\hline High school & 5 & 6.1 \\
\hline \multicolumn{3}{|l|}{ Marital status } \\
\hline Single & 16 & 51.6 \\
\hline Married & 12 & 38.7 \\
\hline Dowager & 2 & 6.5 \\
\hline Divorced & 1 & 3.2 \\
\hline \multicolumn{3}{|l|}{ Comorbidities } \\
\hline Yes & 14 & 45.2 \\
\hline No & 17 & 54.8 \\
\hline \multicolumn{3}{|l|}{ Continuous use of medication } \\
\hline Yes & 9 & 29.0 \\
\hline No & 22 & 71.0 \\
\hline \multicolumn{3}{|l|}{ Self-assessment on health condition } \\
\hline Excellent & 4 & 12.9 \\
\hline Good & 14 & 45.2 \\
\hline Not good & 13 & 41.9 \\
\hline \multicolumn{3}{|l|}{ Reason for hospitalization } \\
\hline Clinic condition & 7 & 22.6 \\
\hline Trauma condition & 24 & 77.4 \\
\hline \multicolumn{3}{|l|}{ Alcoholism } \\
\hline Yes & 11 & 35.5 \\
\hline No & 20 & 64.5 \\
\hline \multicolumn{3}{|l|}{ Smoking } \\
\hline Yes & 5 & 16.1 \\
\hline No & 26 & 83.9 \\
\hline \multicolumn{3}{|l|}{ History of falls } \\
\hline Yes & 25 & 80.64 \\
\hline No & 6 & 19.36 \\
\hline \multicolumn{3}{|l|}{ Consequence of fall $(n=25)$} \\
\hline Fractures & 8 & 25.8 \\
\hline Bruises & 6 & 19.4 \\
\hline Wounds & 11 & 35.5 \\
\hline
\end{tabular}


Table 2. Hit distribution before and after educational intervention mediated by the flipchart with patients hospitalized in the medical clinic $(\mathrm{n}=31)($ Sobral/CE, Brazil, 2019)

\begin{tabular}{|c|c|c|c|c|c|}
\hline \multirow{2}{*}{ Statements } & \multicolumn{2}{|c|}{ Pre-test } & \multicolumn{2}{|c|}{ Post-test } & \multirow{2}{*}{$p$-value* } \\
\hline & $\mathbf{n}$ & $\%$ & $\mathbf{N}$ & $\%$ & \\
\hline 1) Falls only happen when one reaches the ground. & 13 & 41.9 & 30 & 96.8 & .000 \\
\hline 2) Falls can worsen one's health condition. & 31 & 100 & 31 & 100 & - \\
\hline 3) The nursing team has no responsibility on warning patients about their risk of falls. & 24 & 77.4 & 28 & 90.3 & .219 \\
\hline $\begin{array}{l}\text { 4) The nursing team has no responsibility on warning patients about the effects of their } \\
\text { medication. }\end{array}$ & 26 & 83.9 & 28 & 90.3 & .500 \\
\hline 5) Whenever the patient has a question. he should report it to the nursing team. & 31 & 100 & 31 & 100 & - \\
\hline 6) Object on the floor can cause falls. & 31 & 100 & 31 & 100 & - \\
\hline 7) Bed rails in the ward should always be kept low. & 25 & 80.6 & 27 & 87.1 & .688 \\
\hline 8) Objects in constant use should always be accessible. & 31 & 100 & 31 & 100 & - \\
\hline 9) Only the elderly can suffer falls. & 28 & 90.3 & 30 & 96.8 & .500 \\
\hline 10) People with morbid obesity are more likely to fall. & 25 & 80.3 & 31 & 100 & .031 \\
\hline 11) People who wear prostheses or have limited mobility are more likely to fall. & 28 & 90.3 & 30 & 96.8 & .625 \\
\hline $\begin{array}{l}\text { 12) If the patient has a history of falls. he/she should stay in a room further away from } \\
\text { the nursing station. }\end{array}$ & 27 & 87.1 & 24 & 77.4 & .250 \\
\hline $\begin{array}{l}\text { 13) The patient should not wait for his/her companion or a professional of the team if } \\
\text { he/she wants to get up or move around. }\end{array}$ & 24 & 77.4 & 30 & 96.8 & .031 \\
\hline $\begin{array}{l}\text { 14) It is important that the companion always notifies the team if he/she is going to be } \\
\text { away. }\end{array}$ & 30 & 96.8 & 31 & 100 & 1.000 \\
\hline 15) Exercising can help prevent falls from occurring. & 31 & 100 & 31 & 100 & - \\
\hline $\begin{array}{l}\text { 16) Even with limitations, there are alternatives for each person to have stimuli to } \\
\text { strengthen their muscles. }\end{array}$ & 26 & 83.9 & 31 & 100 & .063 \\
\hline $\begin{array}{l}\text { 17) If the fall occurs in the hospital environment, it is important that the patient tries to } \\
\text { get up to call the nursing staff. }\end{array}$ & 17 & 54.8 & 27 & 87.1 & .006 \\
\hline 18) If the fall occurs at home, the patient must get up immediately and ask for help. & 15 & 48.4 & 27 & 87.1 & .000 \\
\hline $\begin{array}{l}\text { 19) If there is a bone injury, the patient should immobilize the limb and never attempt } \\
\text { to correct the injury alone. }\end{array}$ & 25 & 80.6 & 25 & 80.6 & 1.000 \\
\hline $\begin{array}{l}\text { 20) If there is an injury, the patient should wash only with water and cover until he/she } \\
\text { gets to the nearest health service. }\end{array}$ & 20 & 64.5 & 29 & 93.5 & .004 \\
\hline
\end{tabular}

* McNemar Test.

The assessment of patients at potential risk for falls during hospitalization and the provision of health education mediated by educational technologies to patients, family members and caregivers is essential to minimize the occurrence of this adverse event and its resulting damages. ${ }^{[12]}$ In this study, the flipchart stands out as a potential tool to be used to prevent falls, which has attractive illustrations and accessible language that arouse interest for the educational moment and facilitate the acquisition of knowledge on the subject. After the intervention mediated by educational technology, there was a significant increase in correct answers in 13 of the 20 questions in the post-test when compared to the pre-test.

These results converge with a study developed in Australia, in which a fall prevention program was effective to increase the perception of the participants involved about the importance of fall prevention by contributing to the identification of risk factors and the development of safe preventive behav- ior. ${ }^{[13]}$ An observational study implemented in the United States with 1,200 patients and family members demonstrated that the use of educational video is effective for preventing falls in the hospital environment. During the seven-year data collection period, there was a $20 \%$ reduction in the incidence rate of falls and a $40 \%$ reduction in injuries secondary to falls. ${ }^{[14]}$

Another study conducted in Australia showed the effectiveness of educational intervention by telephone support in preventing the occurrence of falls and its complications, such as fractures. ${ }^{[15]}$ There was also compliance with a study carried out in São Paulo with 69 elderly people. The group that received educational intervention on falls had an improvement on their knowledge about risk factors, with an inverse association between the perception of risks and risk factors that they had at home. Participants with greater knowledge are less exposed to risk factors for falls. ${ }^{[16]}$ 
Accordingly, an integrative review study analyzed technologies developed to promote health education for the elderly available in the literature, obtaining in its results 15 articles that mostly reported educational actions aimed at preventing falls. The use of printed materials, software and videos prevailed, but there was also the identification of mock-up and telephone support. The review evidenced effectiveness in the individual use of educational technologies to promote health education. ${ }^{[17]}$

Statements related to the definition of falls (question $1, p$ $=.000$ ), falls in morbidly obese patients (question 10, $p=$ .031 ), patient's behavior in case of a fall (question 13, $p=$ .031 and question 17, $p=.006$ ), the individual's conduct if he/she falls at home (question $18, p=.000$ ) and how to proceed if he/she suffers injuries (question 20, $p=.004$ ) showed a statistically significant increase in correct answers in the post-test.

Many patients were unaware of the concept of falls, considering it only when the patient reaches the floor. Guidance on the definition of falls is important both to reduce underreporting of the occurrence of falls and for training that individual on what to do if it occurs. A study indicates that, when the patient understands what a fall is, he/she becomes more careful in his/her daily life and becomes trained on how to deal with future situations since, normally, when the person avoids falling, he/she ends up supporting him/herself in one of the limbs, leading to post-fall complications. ${ }^{[18]}$

Most participants answered correctly the item about the occurrence of falls only in the elderly. Although older people are more susceptible to falls due to changes in balance and gait associated with aging, this adverse event can occur at any age and in younger people as evidenced in this study. In the United States, a survey of 164,597 elderly people identified that $23 \%$ of participants has suffered at least one fall in recent years, which are associated with more serious injuries and deaths in this population. ${ }^{[19]}$

The question about a higher risk of falls in obese individuals showed statistical significance between pre and post-test. A study conducted in Rio Grande do Sul with 211 elderly falls showed a positive association between obesity and the occurrence of falls. ${ }^{[20]}$ High body mass indexes favor a reduction in postural balance and an increase in the incidence of blunt trauma secondary to falls, which contributes to a high mortality rate and longer hospital stay among obese individuals. $^{[21]}$

Regarding the practice of physical activity to strengthen the muscles, there was consensus among the participants about the benefits of this care for preventing falls. A clinical trial conducted in Canada with 296 elderly people identified that, when applying a strength and balance training exercise program in the intervention group, there was a reduction in the incidence of falls when compared to the elderly who received only routine care. ${ }^{[22]}$

There was a low rate of correct answers in the pre-test on statements related to immediate care after the fall in the hospital and home environment, but participants demonstrated adequate knowledge about care for injuries and wounds. This result corroborates with another study that identified that patients were unaware of post-fall care, but knew about the management of injuries resulting from a fall. Authors justify it by the fact that the fall is still underreported, being common both at home and hospital environments, especially in the elderly. ${ }^{[23]}$

Educational interventions to prevent falls contribute to increase the perception of personal and environmental risk factors that can be modified, in addition to raising awareness of the need to maintain preventive care to prevent falls and associated injuries and increase adherence to the guidelines received. ${ }^{[24]}$ In this perspective, the flipchart stands out as a tool to be used in health education that favors the expansion of patients' knowledge through interactive, dialogic and playful learning.

In Ireland and in Australia, an exploratory study of qualitative description, incorporating focus groups, brings the perception and opinion of the elderly about the use of technology and its potential to contribute to the prevention of falls, highlighting in one of their speeches the importance of carrying out face-to-face moments with health professionals to talk and demonstrate activities in a playful way, increasing the level of knowledge about the perception of the risk of falls, interventions, exercises for their prevention and, thus, guaranteeing self-care to prevent possible adverse events. ${ }^{[25]}$

Thus, if the guidelines on factors associated with falls are increasingly disseminated among the population at risk in hospitals, there will be greater empowerment of these individuals and educational interventions can be implemented according to the needs of each participant. Thus, in order to improve the quality of care provided and favor the reduction of adverse events, members of the multidisciplinary staff, especially nurses, must implement educational interventions by using educational technologies in order to promote health in the hospital environment and increase the co-responsibility of patients in health care in preventing falls.

This study has as limitations the absence of randomization and masking during the implementation of the educational intervention. Thus, it suggests carrying out new experimen- 
tal studies to assess the risks for falls that are prevalent in the hospital environment, and thus reduce adverse events indicators, as well as strengthening the findings of this study regarding the importance of patient education in the hospital environment for the prevention of falls.

\section{Conclusion}

The findings of this study allow us to infer that there was an improvement in knowledge after the educational intervention mediated by the flipchart. The averge of correct answers went from 17 to 20 , so that statistical significance was observed $(p<.000)$. In the analysis of the items, an increase in the number of correct answers was identified in questions about the definition of falls, conduct in the case of suffering falls in the hospital and conduct in case of falls at home.

Therefore, the flipchart is an effective technology for patient education on the prevention of falls in the medical-surgical clinic, favoring the empowerment of participants about the existing risks in hospital environment and preventive care. It is pertinent to carry out educational moments with the nursing team to train them on the use of the flipchart so that it can be implemented in the work routine of these professionals, who responsible for the care and safety of their patients during hospitalization period.

It is also suggested the application of educational interventions with caregivers, as, often, patients are unable to perform or even to understand prevention guidelines. Thus, caregivers can be important in reducing this adverse event by understanding more about existing risks and necessary care.

\section{CONFlicts of INTEREST Disclosure}

The authors declare that there is no conflict of interest.

\section{REFERENCES}

[1] Organização Mundial da Saúde (OMS). FALLS. World Health Organization. 2018.

[2] Avanecean D, Calliste D, Contreras T, et al. Effectiveness of patientcentered interventions on falls in the acute care setting compared to usual care: a systematic review. JBI Database System. Rev Implement Rep. 2017; 15(12): 3006-48. PMid:29219876 https: //doi.org/10.11124/JBISRIR-2016-003331

[3] Najafpour Z, Godarzi Z, Arab Z, et al. Fatores de risco para quedas em pacientes hospitalizados: um estudo prospectivo de controle de casos aninhados. International Journal of Health Policy and Management. 2019; 8(5): 300-306.

[4] Ministério da Saúde. Documento de referência para o Programa Nacional de Segurança do Paciente. Ministério da Saúde; Fundação Oswaldo Cruz; Agência Nacional de Vigilância Sanitária. Brasília, 2014.

[5] Severo IM, et al. Fatores de risco para quedas em pacientes adultos hospitalizados: um estudo caso-controle. Rev. Latino-Am. Enfermagem. 2018; 26.

[6] Cameron ID, et al. Intervenções para prevenir quedas em idosos em unidades de saúde e hospitais. Base de dados Cochrane de revisões sistemáticas. 2018; 9.

[7] Rodrigues MMP, Franco EES, Falcão RMM, et al. Short Educational Intervention On Fall Prevention For Hospitalized Adults And Elderly. International Archives of Medicine. 2017; 9: 1-9.

[8] Naseri C, Mcphail SM, Netto J, et al. Impact of tailored falls prevention education for older adults at hospital discharge on engagement in falls prevention strategies postdischarge: protocol for a process evaluation. Rehabilitation Medicine. 2018; 8(4): 1-7. PMid:29678985 https://doi.org/10.1136/bmjopen-2017-020726

[9] Conselho Nacional de Saúde. Resolução 466/12. Trata de pesquisas em seres humanos e atualiza a resolução 196. Diário oficial de União 12 de dez de 2012.

[10] Pasa TS, et al. Avaliação do risco e incidência de quedas em pacientes adultos hospitalizados. Revista Latino-Americana de Enfermagem. 2017; 25: 2862.
[11] Bittencourt VLL, et al. Factors associated with the risk of falls in hospitalized adult patients. Rev. esc. enferm. USP. 2017; 51. PMid:28746559 https://doi.org/10.1590/s1980-220x2 016037403237

[12] Aguiar JR, et al. Fatores de risco associados à queda em pacientes internados na clínica médica-cirúrgica. Acta paul. Enferm. 2019; 32(6): 617-623. https://doi.org/10.1590/1982-0194201900086

[13] Hill AM, Francis-Coad J, Haines TP, et al. 'My independent streak may get in the way': how old era du lt sres pond to falls prevention education in hospital. BMJ Open. $2016 \mathrm{Jul}$ 26; 6(7): e012363. PMid:27466244 https://doi.org/10.1136/bmjopen-2016-0 12363

[14] Cuttler SJ, Barr-Walker J, Cuttler L. Reducing medical-surgical inpatient falls and injuries with videos, icons and alarms. BMJ Open Qual. 2017; 6(2): e000119. PMid:29450285 https://doi.org/10 $.1136 / \mathrm{bmjoq}-2017-000119$

[15] Barker A, Cameron P, Flicker L, et al. Evaluation of RESPOND, a patient-centred program to prevent falls in older people presenting to the emergency department with a fall: A randomised controlled trial. PLoS Med. 2019; 16(5): e1002807. PMid:31125354 https://doi.org/10.1371/journal.pmed.1002807

[16] Silva VM, et al. Efetividade de uma intervenção múltipla para a prevenção de quedas em idosos participantes de uma Universidade Aberta à Terceira Idade. Rev. bras. geriatr. gerontol. 2019; 22(4): e190032.

[17] Sá GGM, Silva FL, Santos AMR, et al. Technologies that promote health education for the community elderly: integrative review. Rev. Latino-Am. Enfermagem. 2019; 27: e3186.

[18] Reiniack S, Silva CF, Paz M, et al. Notificação de queda do paciente cirúrgico antes e após treinamento em serviço. Cogitare Enferm. 2017 Jan/mar; 22(1): 01-08. https ://doi .org/10.5380/ce.v22i1.4 7656

[19] Jia H, Lubetkin EI, DeMichele K, et al. Prevalence, risk factors, and burden of disease for falls and balance or walking problems among older adults in the U.S. Prev Med. 2019; 126: 105737 PMid:31150739 https://doi.org/10.1016/j.ypmed.2019.0 5.025 
[20] Almeida LMDS, Meucci RD, Dumith SC. Prevalence of falls in elderly people: a population based study. Rev Assoc Med Bras (1992). 2019; 65(11): 1397-1403. PMid:31800903 https://doi .org/10 .1590/1806-9282.65.11.1397

[21] Barry R, Modarresi M, Aguilar R, et al. The Impact of BMI on Adult Blunt Trauma Outcomes. Am Surg. 2019; 85(12): 1354-1362. https://doi.org/10.1177/000313481908501229

[22] Liu-Ambrose T, Davis JC, Best JR, et al. Effect of a Home-Based Exercise Program on Subsequent Falls Among Community-Dwelling High-Risk Older Adults After a Fall: A Randomized Clinical Trial. JAMA. 2019; 321(21): 2092-2100. PMid:31162569 https : //doi.org/10.1001/jama.2019.5795
[23] Alves AM. Construção e validação de cartilha educativa para prevenção de quedas em idosos. 2017. 165 f. Dissertação (Mestrado em Enfermagem) - Faculdade de Farmácia, Odontologia e Enfermagem, Universidade Federal do Ceará. Fortaleza, 2017.

[24] Hayes S, Galvin R, Kennedy C, et al. Interventions for preventing falls in people with multiple sclerosis. Cochrane Database Syst Rev. 2019; 11(11): CD012475.

[25] Mackenzie L, Clifford A. Perceptions of older people in Ireland and Australia about the use of technology to address falls prevention. Ageing \& Society. 2020; 40(2): 369-388. https ://doi .org/10.1 017/S0144686X18000983 